\title{
Diphenylarsinic acid contaminated soil remediation by titanium dioxide (P25) photocatalysis: Degradation pathway, optimization of operating parameters and effects of soil properties
}

\author{
A-nan Wang ${ }^{\mathrm{a}, \mathrm{c}}$, Ying Teng ${ }^{\mathrm{a}}$, Xue-feng $\mathrm{Hu}^{\mathrm{b}}{ }^{\mathrm{b}}$, Long-hua $\mathrm{Wu}^{\mathrm{a}}$, Yu-juan Huang ${ }^{\mathrm{a}}$, \\ Yong-ming Luo ${ }^{\mathrm{a}, \mathrm{b}, *}$, Peter Christie ${ }^{\mathrm{a}}$ \\ a Key Laboratory of Soil Environment and Pollution Remediation, Institute of Soil Science, Chinese Academy of Sciences, Nanjing 210008, China \\ b Yantai Institute of Coastal Zone Research, Chinese Academy of Sciences, Yantai 264003, China \\ c Graduate School of Chinese Academy of Sciences, Beijing 100039, China
}

\section{H I G H L I G H T S}

- DPAA was degraded into arsenate through $\mathrm{TiO}_{2}$ (P25) photocatalytic oxidation.

- Soil/water ratio was more influential on the removal of DPAA in soil by $\mathrm{TiO}_{2}$ (P25).

- Soil properties affected the adsorption of DPAA and the generation of $\mathrm{OH} \bullet$ by $\mathrm{TiO}_{2}$.

\section{A R T I C L E I N F O}

\section{Article history:}

Received 18 February 2015

Received in revised form 12 August 2015

Accepted 1 September 2015

Available online 25 September 2015

Editor: D. Barcelo

\section{Keywords:}

Diphenylarsinic acid

$\mathrm{TiO}_{2}(\mathrm{P} 25)$

Photocatalysis

Electron spin resonance
GRA P H I C A L A B S T R A C T

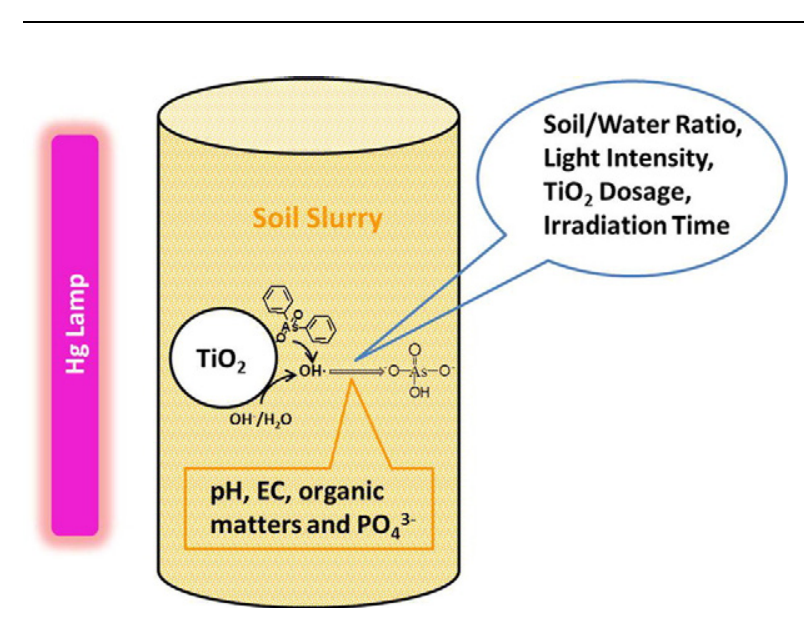

A B S T R A C T

Diphenylarsinic acid (DPAA) is formed during the leakage of arsenic chemical weapons in sites and poses a high risk to biota. However, remediation methods for DPAA contaminated soils are rare. Here, the photocatalytic oxidation (PCO) process by nano-sized titanium dioxide $\left(\mathrm{TiO}_{2}\right)$ was applied to degrade DPAA in soil. The degradation pathway was firstly studied, and arsenate was identified as the final product. Then, an orthogonal array experimental design of $\mathrm{L}_{9}(3)^{4}$, only 9 experiments were needed, instead of 81 experiments in a conventional one-factor-at-a-time, was used to optimize the operational parameters soil:water ratio, $\mathrm{TiO}_{2}$ dosage, irradiation time and light intensity to increase DPAA removal efficiency. Soil:water ratio was found to have a more significant effect on DPAA removal efficiency than other properties. The optimum conditions to treat $4 \mathrm{~g}$ soil with a DPAA concentration of $20 \mathrm{mg} \mathrm{kg}^{-1}$ were found to be a $1: 10$ soil: water ratio, $40 \mathrm{~mW} \mathrm{~cm}^{-2}$ light intensity, $5 \% \mathrm{TiO}_{2}$ in soil, and a 3-hour irradiation time, with a removal efficiency of up to $82.7 \%$. Furthermore, this method (except for a change in irradiation time from 3 to $1.5 \mathrm{~h}$ ) was validated in nine different soils and the removal efficiencies ranged from 57.0 to $78.6 \%$. Removal efficiencies were found to be negatively correlated with soil

\footnotetext{
* Corresponding author at: 17 Chunhui Road, Laishan District, Yantai, China.

E-mail address: ymluo@yic.ac.cn (Y. Luo).
} 
electrical conductivity, organic matter content, $\mathrm{pH}$ and total phosphorus content. Finally, coupled with electron spin resonance (ESR) measurement, these soil properties affected the generation of $\mathrm{OH} \bullet$ by $\mathrm{TiO}_{2}$ in soil slurry. This study suggests that $\mathrm{TiO}_{2}$ photocatalytic oxidation is a promising treatment for removing DPAA from soil.

C 2015 Elsevier B.V. All rights reserved.

\section{Introduction}

Diphenylarsinic acid (DPAA) is the hydrolytic or oxidative derivative of diphenylchloroarsine and diphenylcyanoarsine, both of which were once used for the manufacture of arsenical chemical weapons (Daus et al., 2010). After World War II most of these chemicals were discarded and subsequently, due to leakage, have led to serious arsenic pollution in several parts of China (Wada et al., 2006), Japan (Hanaoka et al., 2005) and Europe (Daus et al., 2008; Hempel et al., 2009). DPAA has been detected as one of the main arsenic species in these contaminated sites (Ishizaki et al., 2005). DPAA has high neural and genetic toxicity (Ishii et al., 2004) and is difficult to be degraded under natural conditions (Hempel et al., 2009). Along with its high mobility (Maejima et al., 2011; Wang et al., 2013) DPAA poses a high risk to humans. In 2002 DPAA was reported to be the culprit in a serious arsenic poisoning accident in Kamisu, Japan, when local people drank underground water from a well near a deposit of arsenic chemical weapons (Hanaoka et al., 2006).

Hence, it is important to find an effective decontamination method for the rapid removal of DPAA from contaminated soils. A possible remediation method for DPAA contamination is to degrade the DPAA completely into inorganic arsenics and then to phytoextract the inorganic forms using a hyperaccumulator plant species such as Pteris vittata (Ma et al., 2001).

The biodegradation capability of DPAA has been studied by Nakamiya et al. (2007) and Harada et al. (2010). They isolated three bacterial strains that could directly degrade DPAA at low concentrations (5-10 mg/L). Guan et al. (2012a) also found the transformation of DPAA in soils can be enhanced under sulfate-reducing conditions. However, the process was time-consuming and most of DPAA was transformed only into other organic forms, with no detailed report on the detail yield of inorganic arsenics.

$\mathrm{TiO}_{2}$ photocatalytic oxidation (PCO) is a promising technology for elimination of organic pollutants (Chong et al., 2010), allowing degradation of organic arsenics into inorganic forms. Monomethylarsonic (MMA), dimethylarsinic acids (DMA) (Xu et al., 2007b, 2008) and phenylarsonic acid (PAA) (Zheng et al., 2010) have been reported to degraded to arsenate in $\mathrm{TiO}_{2}$ solution and $\mathrm{OH}$ • plays a primary role in the PCO. Moreover, nanocrystalline $\mathrm{TiO}_{2}$ can also work as an absorbent for the removal of inorganic/organic arsenics (Guan et al., 2012b). However, there is no related report on DPAA.

Recently $\mathrm{TiO}_{2}$ PCO has also gained scientific interest for treating pollutants adsorbed onto soil surfaces. Two main methods are utilized. One method is to wash the soils contaminated by PAHs or PCBs with nonpolar solvents and then treat the solvent washings with $\mathrm{TiO}_{2} \mathrm{PCO}$ to eliminate the contaminants (Davezza et al., 2013). The other method is to add $\mathrm{TiO}_{2}$ directly to the soil to degrade organic pollutants under UV irradiation (Zhang et al., 2008). The first method needs multiple treatments to remove contaminants completely. The second one is usually limited by the poor depth of light penetration into soils (Balmer et al., 2000).

The efficiency of photodegradation of organic pollutants by $\mathrm{TiO}_{2}$ depends mainly on the adsorption capacity for the pollutant and the ROS quantum yield of the catalyst (Fujishima et al., 2000). The effects of common environmental conditions on the adsorption of arsenicals onto $\mathrm{TiO}_{2}$ surface have been studied a lot (Jiang et al., 2005; Xu et al., 2008 ) but studies on the influence of soil properties on the generation of ROS by $\mathrm{TiO}_{2}$ are very rare. $\mathrm{Ng}$ et al. (2013) once reported the production of $\mathrm{OH}$ by $\mathrm{TiO}_{2}$ was influenced by its stability in solution, and the stability of $\mathrm{TiO}_{2}$ in soil slurries appeared to be correlated with soil properties (Fang et al., 2009). Thus, it can be inferred that the generation of ROS by $\mathrm{TiO}_{2}$ in soil can also be affected by soil properties.

In the present study $\mathrm{TiO}_{2}$ (P25) was used to directly degrade the DPAA adsorbed onto soil. Soil was transformed into slurry and stirred under high-pressure mercury lamp irradiation to break through the limitation of light penetration into the soil surface (Huang and Hong, 2000). The aims of the study were to understand the PCO pathway of DPAA by $\mathrm{TiO}_{2}$, to optimize and validate an efficient remediation method for DPAA-contaminated soils which would be affected by irradiation time, $\mathrm{TiO}_{2}$ dosage, irradiation intensity and soil:water ratio, and to elucidate the possible mechanism of DPAA degradation efficiency as affected by soil properties (soil electrical conductivity, soil $\mathrm{pH}$, organic matters content, and phosphate content) and especially their effects on the generation of ROS by $\mathrm{TiO}_{2}$.

\section{Materials and methods}

\subsection{Reagents}

DPAA (purity 97\%) was purchased from Wako Company, Osaka, Japan. PAA (purity 99\%) was provided by Aladdin Company, Shanghai, China. Nanocrystalline titanium dioxide $\left(\mathrm{TiO}_{2}\right.$, Degussa P25, a mixture of $80 \%$ anatase and $20 \%$ rutile with an average surface area of $50 \mathrm{~m}^{2} \mathrm{~g}^{-1}$, size 20-30 nm) was purchased from Degussa Company, Essen, Germany. Humic acids (HA, Fluka no. 53680) was purchased from Sigma Aldrich, Inc. Milwaukee, WI, and its stock solution ( $200 \mathrm{mg} \mathrm{L}^{-1}$ ) was prepared according to Qu et al. (2012) procedure. High-performance liquid chromatography (HPLC) grade acetonitrile was acquired from Tedia Inc., Fairfield, $\mathrm{OH}$. Ultrapure water (18.2 M $\Omega$ ) was obtained using a Millipore-Milli Q system (Millipore Corporation, Billerica, MA) and was used to prepare all necessary solutions. Other chemical reagents were of analytical grade and used as received.

\subsection{Preparation of soil and clay samples}

The Ca-saturated smectite and hematite were purchased from Zhejiang Geology. Goethite and $\mathrm{Al}_{2} \mathrm{O}_{3} \cdot 3 \mathrm{H}_{2} \mathrm{O}$ were artificially synthesized (detailed in $\mathrm{SI}$ ). All soil samples were obtained from the surface layer (0-10 cm depth) of soils collected from different Chinese provinces. They were air-dried and passed through a $0.25 \mathrm{~mm}$ sieve prior to use. Each soil was then artificially contaminated with DPAA at a level of $20 \mathrm{mg} \mathrm{kg}^{-1}$. The detailed procedure was as follows. soil (10 g) was placed in a petri-dish, added with $5 \mathrm{~mL}$ DPAA stock solution ( $400 \mathrm{mg} \mathrm{L}^{-1}$ ), and then the soil slurry was equilibrated for $2 \mathrm{~d}$ to allow the sorption of DPAA onto the soil particles. The soil slurry was vacuum freeze dried, grinded and passed through a $0.25 \mathrm{~mm}$ sieve, and mixed thoroughly with another $90 \mathrm{~g}$ soil.

\subsection{Photocatalytic degradation of $\mathrm{DPAA}$ in $\mathrm{TiO}_{2}$ slurry}

All photocatalytic reactions were conducted in a merry-go-round photochemical reactor equipped with a $500 \mathrm{~W}$ high pressure mercury lamp at the room temperature $\left(25^{\circ}\right)$. The light intensity was changed by adjusting the electrical current. Fifty-mL Pyrex glass tubes which can filter light with a wavelength $<300 \mathrm{~nm}$ were employed to contain the reaction solutions or soil slurries. 
Table 1

Parameters and levels of the orthogonal experimental design.

\begin{tabular}{llllll}
\hline Parameters & Symbol & \multicolumn{2}{l}{ Level } & \multirow{2}{*}{ Unit } \\
\cline { 3 - 5 } & & 1 & 2 & 3 & \\
\hline Soil/water ratio & $\mathrm{A}$ & $1: 1$ & $1: 2$ & $1: 5$ & $\mathrm{M}(\mathrm{g}): \mathrm{v}(\mathrm{mL})$ \\
$\mathrm{TiO}_{2}$ dosage & $\mathrm{B}$ & 1 & 2 & 5 & $\%$ \\
Light intensity & $\mathrm{C}$ & 1.6 & 8 & 40 & $\mathrm{~mW} \mathrm{~cm}^{-2}$ \\
Irradiation time & $\mathrm{D}$ & 1.5 & 3 & 6 & hour \\
\hline
\end{tabular}

Thirty-mL dispersion containing $1000 \mathrm{mg} \mathrm{L}^{-1} \mathrm{TiO}_{2}$ and $20 \mathrm{mg} \mathrm{L}^{-1}$ DPAA was prepared and magnetically stirred in the dark for $30 \mathrm{~min}$ prior to irradiation (30 min of stirring was sufficient to reach adsorption equilibrium). The dispersion was then transferred to the photochemical reactor and was stirred constantly during irradiation. The light intensity was $40 \mathrm{~mW} \mathrm{~cm}^{-2}$. Samples were withdrawn at different time intervals and filtered through a 0.22- $\mu \mathrm{m}$ membrane filter (Nylon, Anpel Scientific Instrument Co., Ltd., Shanghai, China) for subsequent analysis.

\subsection{Optimization of the degradation method of DPAA by $\mathrm{TiO}_{2}$}

The degradation method was optimized using a multifactorial orthogonal experiment. Four parameters, namely soil/water ratio, $\mathrm{TiO}_{2}$ dosage, light intensity and irradiation time, were studied at three levels using an $\mathrm{L}_{9}(3)^{4}$ orthogonal array as shown in Table 1 . In conventional one-factor-at-a-time design, the number of experiments required is $3^{4}=81$. However, using the orthogonal design the number of experiments can be reduced to 9 with a considerable saving of time and cost.

Three statistical coefficients (K, R and F-ratio) were used to evaluate the orthogonal data. In this study, $\mathrm{K}$ was the sum of the degradation efficiencies for each impact factor at each level, and $\mathrm{k}$ was the average of $\mathrm{K}$ and used to determine the optimum combination of experimental conditions. The higher the $\mathrm{k}$ value the higher was the removal efficiency of the factor considered. The extreme difference $\mathrm{R}$ represented degree of the influence of various parameters on the removal efficiency. The larger the $\mathrm{R}$ value the more substantial influence was the corresponding factor on the removal efficiency. F-ratio was used to compare the critical F value, a statistic that can be found in most books on statistics and experimental design (Montgonery, 2001), so as to evaluate whether or not the impact factors were statistically significant. The F-ratio was calculated using the method previously described by Gonder et al. (2010).

An accurately weighed soil sample of $4.0 \mathrm{~g}\left(\mathrm{M}_{0}\right)$ was placed in a Pyrex glass tube and mixed with a certain amount of $\mathrm{TiO}_{2}$ powder and pure water at a given volume (Vs). The whole mixture was then irradiated for a given period with a different light intensity. Multifactor orthogonal experiments were applied to optimize the degradation conditions and the soil tested was BA-1. The orthogonal arrays are detailed in Table 1. After irradiation the soil slurry was carefully transferred to a centrifuge tube and was centrifuged at $2000 \mathrm{rev} \mathrm{min}^{-1}$ for $15 \mathrm{~min}$. The supernatant was collected to determine the concentration of DPAA (Cs). The residual soil was then extracted with $0.1 \mathrm{M} \mathrm{Na}_{2} \mathrm{HPO}_{4}$ to determine the residual DPAA in soil $(\mathrm{Cr})$. The degradation efficiency $(\mathrm{Y})$ of DPAA was expressed according to the following equation:

$Y=\frac{C O M 0-(C s V s+C r M 0)}{C O M 0} \times 100 \%$

where $C_{0}$ was the initial concentration of DPAA in prepared contaminated soil.

The optimal degradation method condition was also applied to nine different soils to study the effects of soil properties on the removal efficiency of DPAA.

\subsection{ESR studies}

The ESR study was conducted using mixed slurry of $0.2 \%(\mathrm{w} / \mathrm{v})$ soil clays, $0.1 \%(\mathrm{~g}: \mathrm{mL}) \mathrm{TiO}_{2}$ powders and $0.1 \mathrm{M}$ spin trapping agent 5,5dimethyl-1-pyrroline-N-oxide (DMPO, 97\%, Sigma Aldrich) in various electrolytes as needed. One $\mathrm{mL}$ of the resulting slurry was then injected into a borosilicate glass capillary and irradiated with a $200 \mathrm{~W}$ mercury lamp for 1 min in the cavity of an ESR spectrometer (Bruker EMX 10/ 12 , Germany) at room temperature. The changes in peak intensities of DMPO-adducts in ESR spectra were used to indicate changes in concentration of hydroxyl radicals according to Fang et al. (2013). The ESR settings were: modulation frequency $100 \mathrm{kHz}$, modulation amplitude 2.00 $125 \mathrm{G}$, microwave frequency $9.40 \mathrm{GHz}$ and power $5.10 \mathrm{~mW}$.

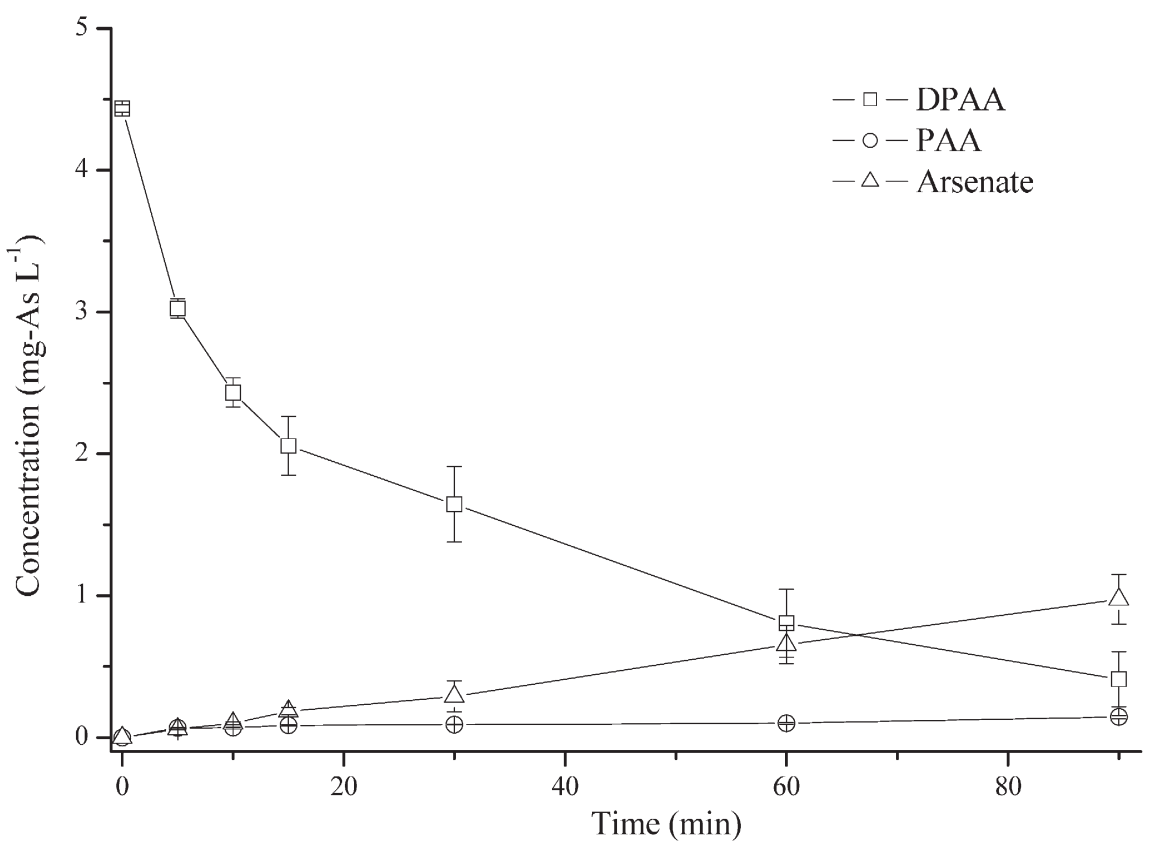

Fig. 1. Photocatalytic reaction kinetics of DPAA, PAA and inorganic As in $\mathrm{P}_{2} 5-\mathrm{TiO}_{2}$ slurry $\left(\mathrm{IS}=1 \mathrm{mM} \mathrm{NaNO}_{3}, \mathrm{pH}=4.5\right)$. 


\subsection{Analytical method}

The concentration of DPAA was determined by HPLC (Shimadzu, Japan) equipped with a Shimadzu VP-ODS $\mathrm{C}_{18}$ column $(4.6 \times 150 \mathrm{~mm}$, $5 \mu \mathrm{m})$. The mobile phase was $19 \%$ acetonitrile and $81 \% 0.02 \mathrm{~mol} \mathrm{~L}^{-1}$ in $\mathrm{KH}_{2} \mathrm{PO}_{4}$ solution ( $\mathrm{pH} 2.7$ ). The detector wavelength was $220 \mathrm{~nm}$. The minimum detection limit of DPAA was $0.1 \mathrm{mg} \mathrm{L}^{-1}$ and the recovery was 95.9\%. The concentration of PAA was determined using a Thermo Fisher TSQ Quantum Access MAX triple stage quadrupole mass spectrometer equipped with an Ion Max ${ }^{\mathrm{TM}}$ source with Negative HESI mode. Mass spectrometry detection was performed under the selective reaction monitoring (SRM) mode. A SunFire $C_{18}$ column $(4.6 \times 250 \mathrm{~mm}$, $5 \mu \mathrm{m}$, Waters Corp., Milford, MA) was used. The mobile phase was $19 \%$ acetonitrile and $81 \%$ acetic acid solution $(0.1 \%, \mathrm{pH}=2.7)$ at a flow rate of $0.8 \mathrm{~mL} \mathrm{~min}{ }^{-1}$. The minimum detection limit of PAA was $0.1 \mathrm{mg} \mathrm{L}^{-1}$ and the recovery was $104.1 \%$. Main organic arsenical intermediates were identified with an LCQ Fleet ion-trap spectrometer (Thermo Fisher Scientific, Waltham, MA) operated in negative-ion mode. The chromatographic conditions were the same as those employed for PAA determination. The inorganic arsenics were analyzed by LC-ICP-MS (Williams et al., 2007; Wu et al., 2011).

\section{Results and discussion}

3.1. Photodegradation of DPAA in $\mathrm{TiO}_{2}$ slurry and possible degradation pathways

The $\mathrm{P} 25-\mathrm{TiO}_{2}$ photocatalytical oxidation of DPAA was studied to investigate the main end-products and possible reaction pathway. As shown in Fig. 1, DPAA was reduced from the initial concentration of


nate concentration increased to $0.98 \mathrm{mg} \mathrm{As} \mathrm{L}^{-1}$ and PAA was also formed in solution but its concentration at the end was only $0.14 \mathrm{mg}$ As $\mathrm{L}^{-1}$. In control experiments there were no obvious losses of DPAA in the absence of $\mathrm{TiO}_{2}$. The $20 \%$ decrease of DPAA concentration in the $\mathrm{TiO}_{2}$ slurry without light irradiation was due to the adsorption of DPAA onto the $\mathrm{TiO}_{2}$ surfaces and the amount adsorbed was reported as $(2896.1 \pm 96.2) \mathrm{mg} \mathrm{kg}^{-1}$ (Wang et al., 2014), indicating that the $\mathrm{TiO}_{2}$ efficiently absorbed DPAA just as it did for other arsenics (Guan et al., 2012b).

Intermediates other than inorganic arsenics and PAA were also identified to elucidate the possible reaction pathways involved in the photocatalytic degradation of DPAA. The ion chromatography and mass
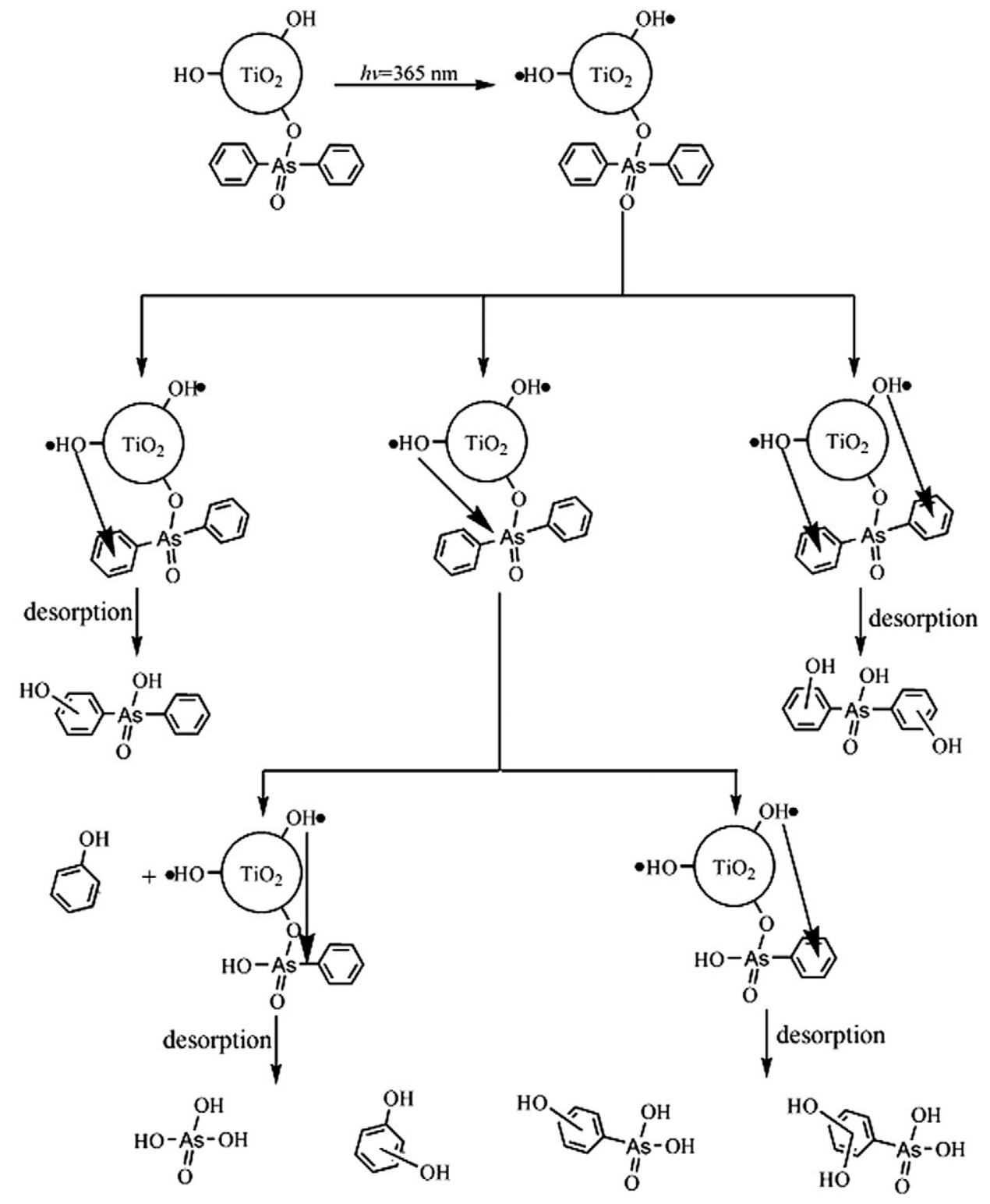

Fig. 2. Proposed photocatalytic degradation pathway for DPAA. 
Table 2

$\mathrm{L}_{9}\left(3^{4}\right)$ orthogonal matrix, experimental data and statistical analysis.

\begin{tabular}{|c|c|c|c|c|c|}
\hline No. & $\begin{array}{l}\text { A } \\
\text { (Soil/water } \\
\text { ratio) M } \\
(\mathrm{g}): \mathrm{v}(\mathrm{mL})\end{array}$ & $\begin{array}{l}\mathrm{B} \\
\left(\mathrm{TiO}_{2}\right. \\
\text { dosage }) \\
\%\end{array}$ & $\begin{array}{l}\text { C } \\
\text { (Light } \\
\text { intensity) } \\
\mathrm{mW} \\
\mathrm{cm}^{-2}\end{array}$ & $\begin{array}{l}\text { D } \\
\text { (Irradiation } \\
\text { time) } \\
\text { hours }\end{array}$ & $\begin{array}{l}\text { Degradation } \\
\text { efficiency } \\
(\%)\end{array}$ \\
\hline 1 & $1: 1$ & $1 \%$ & 1.6 & $1.5 \mathrm{~h}$ & $24.5 \%$ \\
\hline 2 & $1: 1$ & $2 \%$ & 8 & $3 \mathrm{~h}$ & $21.6 \%$ \\
\hline 3 & $1: 1$ & $5 \%$ & 40 & $6 \mathrm{~h}$ & $36.8 \%$ \\
\hline 4 & $1: 2$ & $1 \%$ & 8 & $6 \mathrm{~h}$ & $21.2 \%$ \\
\hline 5 & $1: 2$ & $2 \%$ & 40 & $1.5 \mathrm{~h}$ & $22.4 \%$ \\
\hline 6 & $1: 2$ & $5 \%$ & 1.6 & $3 \mathrm{~h}$ & $25.7 \%$ \\
\hline 7 & $1: 5$ & $1 \%$ & 40 & $3 \mathrm{~h}$ & $53.6 \%$ \\
\hline 8 & $1: 5$ & $2 \%$ & 1.6 & $6 \mathrm{~h}$ & $37.2 \%$ \\
\hline 9 & $1: 5$ & $5 \%$ & 8 & $1.5 \mathrm{~h}$ & $38.1 \%$ \\
\hline K1 & 82.9 & 99.3 & 87.4 & 85.0 & \\
\hline $\mathrm{K} 2$ & 69.3 & 81.2 & 80.9 & 100.9 & \\
\hline K3 & 128.9 & 100.6 & 112.8 & 95.2 & \\
\hline k1 & 27.6 & 33.1 & 29.1 & 28.3 & \\
\hline $\mathrm{k} 2$ & 23.1 & 27.1 & 27.0 & 33.6 & \\
\hline k3 & 43.0 & 33.5 & 37.6 & 31.7 & \\
\hline $\mathrm{R}$ & 19.9 & 6.4 & 10.6 & 5.3 & \\
\hline Optimum level & $1: 5$ & $5 \%$ & 40 & 3 & \\
\hline $\begin{array}{l}\text { Optimal } \\
\text { combination }\end{array}$ & А3B3C3D2 & & & & \\
\hline F-ratio & 165.3 & 19.6 & 50.2 & 14.5 & \\
\hline $\mathrm{F}_{\mathrm{Cv}}^{\mathrm{a}}$ & 6.01 & 6.01 & 6.01 & 6.01 & \\
\hline
\end{tabular}

a Critical F value. Confidence level: $99 \%$.

spectra of the HPLC-MS analysis were presented in Figure S1 and S2. The typical process of $\mathrm{TiO}_{2}$ photocatalysis was initiated mainly by an oxidative path (electrophilic reaction by positive holes or hydroxylation by hydroxyl radicals) (Dai et al., 2008; Zhu et al., 2013). According to our previous ROS quenching experiments (Wang et al., 2014), in which the effects of various ROS scavengers on the photodegradation rate of DPAA by $\mathrm{TiO}_{2}$ was studied to elucidate the contribution of different ROS in the reaction (Beltran et al., 1998; Minero et al., 2000), the hydroxyl radicals would play a key role in the photocatalytic degradation of DPAA. Therefore, the formation of arsenate and PAA would be the substitution of aromatic rings by hydroxyl groups and the fragment ions with $\mathrm{m} / \mathrm{z}$ of 218,277 , and 293 can be inferred as monohydroxylated
PAA, monohydroxylated and dihydroxylated DPAA, respectively. The possible degradation pathway is proposed in Fig. 2. During the photocatalytic degradation of DPAA, $\mathrm{TiO}_{2}$ absorbed UV light to generate electron-hole pairs (Hong et al., 1998). Then $\mathrm{OH} \bullet$ could add on the aromatic group or break the As-C bond and inorganic arsenics, PAA and hydroquinone were ultimately evolved via different oxidation steps.

On the basis outlined above, $\mathrm{TiO}_{2}$ (P25) cannot completely convert DPAA into inorganic arsenics but can adsorb DPAA and its final arsenical products, all which suggests that $\mathrm{TiO}_{2}$ can be used as a useful material for treating DPAA pollution.

\subsection{Optimization of the photocatalytic degradation method for DPAA con- taminated soil}

As shown in Table 2, the results showed that the highest $\mathrm{k}$ value for each factor was at the second level for irradiation time $(3 \mathrm{~h})$ and the third level for the other three factors (soil:water ratio $=1: 5$, TiO2 dosage $=5 \%$, light intensity $=40 \mathrm{~mW} \mathrm{~cm}^{-2}$ ). The regression coefficient $\mathrm{R}$ ranged from large to small as follows: soil: water ratio $>$ light intensity $>$ irradiation time $>$ dosage of $\mathrm{TiO}_{2}$. Therefore the optimum combination might be A3B3C3D2. The F-ratio was used in the variance test to evaluate whether or not the impact factors were statistically significant. According to the variance test, all four impact factors significantly influenced the removal efficiency of DPAA in soil slurry at the $99 \%$ confidence level.

Increasing the volume of water promoted removal efficiency more effectively than the other factors, perhaps because adding more water diluted the whole reaction system, thus promoting the penetration of UV light so as to increase $\mathrm{TiO}_{2}$ adsorption of UV light and thereby increase degradation efficiency. The photo-reaction depends mainly on the number of photons adsorbed (Konstantinou and Albanis, 2004) and the high light intensity can supply sufficient protons to make better use of the photocatalytic ability of $\mathrm{TiO}_{2}$. However, due to the large amounts of organic matter (OM) in soils, many of the $\mathrm{TiO}_{2}$ particles would be embedded by OM (Yang et al., 2009) or the generated $\mathrm{OH}^{\bullet}$ can also be consumed by OM (Bachman and Patterson, 1999), resulting in an increase in the dosage of $\mathrm{TiO}_{2}$ having little effect on the removal efficiency of DPAA. Basically, most of the photocatalytic reactions can be fitted by first-order reaction kinetics (Xu et al., 2007a), thus the initial

Table 3

Selected soil physic-chemical properties and the degradation efficiency of DPAA in soil slurry.

\begin{tabular}{|c|c|c|c|c|c|c|c|c|c|c|c|c|}
\hline Soil & $\begin{array}{l}\text { Electrical } \\
\text { conductivity }\end{array}$ & $\mathrm{pH}$ & $\begin{array}{l}\mathrm{SOMg} \\
\mathrm{kg}^{-1}\end{array}$ & $\begin{array}{l}\text { CEC cmol } \\
\mathrm{kg}^{-1}\end{array}$ & $\begin{array}{l}\text { Total P mg } \\
\mathrm{kg}^{-1}\end{array}$ & $\begin{array}{l}\text { Total Fe g } \\
\mathrm{kg}^{-1}\end{array}$ & $\begin{array}{l}\text { Total Al g } \\
\mathrm{kg}^{-1}\end{array}$ & $\begin{array}{l}\mathrm{Fe}_{\mathrm{Ox}}^{\mathrm{a}} \mathrm{g} \\
\mathrm{kg}^{-1}\end{array}$ & $\begin{array}{l}\mathrm{Fe}_{c \mathrm{c}}^{\mathrm{b}} \mathrm{g} \\
\mathrm{kg}^{-1}\end{array}$ & $\begin{array}{l}\mathrm{Al}_{\mathrm{OX}}^{\mathrm{a}} \mathrm{g} \\
\mathrm{kg}^{-1}\end{array}$ & $\begin{array}{l}\mathrm{Al}_{\mathrm{cd}}^{\mathrm{b}} \mathrm{g} \\
\mathrm{kg}^{-1}\end{array}$ & Classification \\
\hline BA-1 & 85 & 6.85 & 25.81 & 30.31 & 553.8 & 32.78 & 68.18 & 3.69 & 10.31 & 1.51 & 3.61 & Phaeozems \\
\hline HRB-1 & 115 & 6.87 & 35.32 & 26.18 & 806.7 & 26.93 & 66.51 & 0.78 & 7.75 & 1.26 & 3.55 & Phaeozems \\
\hline QX-3 & 133 & 6.27 & 21.02 & 13.3 & 1335 & 28.65 & 52.23 & 1.24 & 9.94 & 0.7 & 2.09 & Luvisols \\
\hline QX-2 & 47 & 5.19 & 11.55 & 18.98 & 477.8 & 35.6 & 62.97 & 0.57 & 16.68 & 0.88 & 3.68 & Luvisols \\
\hline QX-1 & 106 & 6.63 & 25.35 & 14.41 & 443.9 & 23 & 49.47 & 2.01 & 19.62 & 1.37 & 4.46 & Luvisols \\
\hline QX-0 & 71 & 5.38 & 9.76 & 17.36 & 329 & 41.61 & 71.34 & 3.48 & 11.89 & 0.74 & 2.51 & Luvisols \\
\hline YJ-0 & 32 & 5.01 & 5.47 & 8.76 & 220.8 & 35.37 & 74.69 & 1.2 & 24.07 & 1.73 & 6.24 & Acrisols \\
\hline YJ-5 & 38 & 4.52 & 10.89 & 5.23 & 262.5 & 14.09 & 28.63 & 0.87 & 8.67 & 0.73 & 3.66 & Acrisols \\
\hline YJ-7 & 52 & 6.23 & 15.7 & 11.57 & 883.8 & 42.09 & 79.64 & 1.66 & 30.71 & 1.53 & 7.29 & Acrisols \\
\hline \multicolumn{8}{|c|}{ Texture (v/v) \% } & & & & \multicolumn{2}{|c|}{ Degradation efficiency (\%) } \\
\hline \multicolumn{3}{|l|}{$\begin{array}{l}\text { Clay } \\
(<2 \mu \mathrm{m})\end{array}$} & \multicolumn{3}{|c|}{$\begin{array}{l}\text { Silt } \\
(2-20 \mu \mathrm{m})\end{array}$} & & \multicolumn{4}{|l|}{$\begin{array}{l}\text { Sand } \\
(20-2000 \mu \mathrm{m})\end{array}$} & & \\
\hline \multicolumn{3}{|l|}{17.7} & \multicolumn{3}{|c|}{45.3} & & \multicolumn{4}{|l|}{36.9} & \multicolumn{2}{|l|}{72.15} \\
\hline \multicolumn{3}{|l|}{9.2} & \multicolumn{3}{|c|}{50.2} & & \multicolumn{4}{|l|}{40.6} & \multicolumn{2}{|l|}{56.97} \\
\hline \multicolumn{3}{|l|}{7.7} & \multicolumn{3}{|c|}{55.2} & & \multicolumn{4}{|l|}{37.1} & \multicolumn{2}{|l|}{59.11} \\
\hline \multicolumn{3}{|l|}{10.7} & \multicolumn{3}{|c|}{61.4} & & \multicolumn{4}{|l|}{27.9} & \multicolumn{2}{|l|}{76.14} \\
\hline \multicolumn{3}{|l|}{7.4} & \multicolumn{3}{|c|}{57.0} & & \multicolumn{4}{|l|}{35.6} & \multicolumn{2}{|l|}{64.15} \\
\hline \multicolumn{3}{|l|}{12.6} & \multicolumn{3}{|c|}{64.1} & & \multicolumn{4}{|l|}{23.3} & \multicolumn{2}{|l|}{73.97} \\
\hline \multicolumn{3}{|l|}{15.5} & \multicolumn{3}{|c|}{31.5} & & \multicolumn{4}{|l|}{53.6} & 78.58 & \\
\hline 6.8 & & & & 30.9 & & & 62.3 & & & & 74.5 & \\
\hline 14.8 & & & & 59.9 & & & 25.3 & & & & 72.92 & \\
\hline
\end{tabular}

\footnotetext{
${ }^{\mathrm{a}} \mathrm{Fe}_{\mathrm{OX}}$ and $\mathrm{Al}_{\mathrm{OX}}$ mean amorphous $\mathrm{Fe}$ and $\mathrm{Al}$ extracted by acidified ammonium oxalate buffer.

b $\mathrm{Fe}_{\mathrm{cd}}$ and $\mathrm{Al}_{\mathrm{cd}}$ mean Citrate-Dithionite (CD) extractable Fe and $\mathrm{Al}$.
} 
Table 4

Correlation coefficients between soil properties and degradation efficiency.

\begin{tabular}{|c|c|c|c|c|c|c|c|c|c|c|c|}
\hline & Electrical conductivity & $\mathrm{pH}$ & SOM & CEC & $\mathrm{Fe}_{\mathrm{OX}}$ & $\mathrm{Fe}_{\mathrm{cd}}$ & Total Fe & $\mathrm{Al}_{\mathrm{OX}}$ & $\mathrm{Al}_{\mathrm{cd}}$ & Total Al & Total P \\
\hline Degradation efficiency & $-0.931^{* *}$ & $-0.705^{*}$ & $-0.839^{* *}$ & -0.326 & 0.161 & 0.420 & 0.345 & 0.156 & 0.411 & 0.191 & $-0.700^{*}$ \\
\hline
\end{tabular}

reaction rate was more rapid than at later stages of the reaction. Thus, the irradiation time also had little influence on removal efficiency.

The optimization degradation method A3B3C3D2 could lead to a removal efficiency of $64.8 \%$ of DPAA in BA-1. Considering the soil:water ratio had a more significant impact on removal efficiency, the soil: water ratio was changed to $1: 10$ and then the removal efficiency increased to $82.7 \%$, degrading most part of the DPAA in BA- 1 soil.

\subsection{Effects of soil properties on the removal efficiency of DPAA by $\mathrm{TiO}_{2} \mathrm{PCO}$}

\subsubsection{Removal efficiencies of DPAA in various soils by $\mathrm{TiO}_{2}$ photocatalytical} oxidation

The optimum remediation method A3B3C3D2 was also validated in different soils which were typical of the regions subject to DPAA contamination in China ( $\mathrm{Tu}, 2011)$. The soil properties are summarized in Table 3. In the study, the irradiation time was reduced to $1.5 \mathrm{~h}$ for better elucidating the effects of various soils on the degradation efficiency because the DPAA in some Acrisols and Luvisols soils was undetected after $3 \mathrm{~h}$ of irradiation in preliminary study. As shown in Table 3 the photodegradation efficiency in 9 soils varied, ranging from 57.0 to $78.6 \%$, with the lowest removal efficiency found in soil HRB-1, and when the irradiation time was increased to $3 \mathrm{~h}$ the removal efficiency in this soil also increased to $68.7 \%$. This optimum remediation method could be used widely in other soil types.

Correlation analysis was performed to define the relationship between degradation efficiency and soil properties and the results show that degradation efficiency was significantly negatively related to soil electrical conductivity, organic matter content, $\mathrm{pH}$ value and total

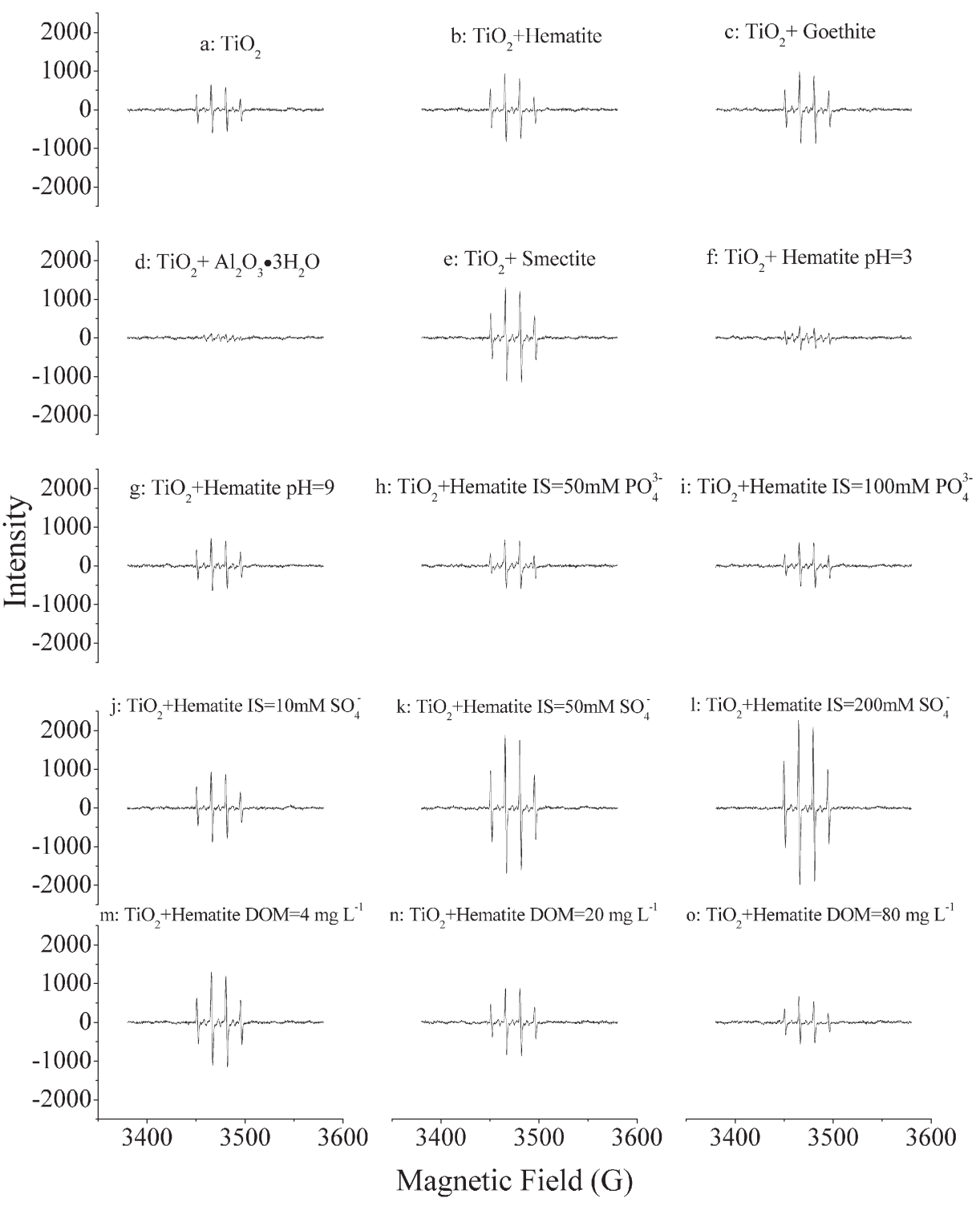

Fig. 3. ESR spectra of samples a-o. If needed the tested slurry contained $\mathrm{TiO}_{2}$ and hematite, $\mathrm{pH} 5.5$, IS $=1 \mathrm{mM} \mathrm{Na}_{2} \mathrm{SO}_{4}$. Irradiation time was 1 min. 
phosphorus (Table 4). This result can be attributed to the effects of these parameters on the adsorption of DPAA onto $\mathrm{TiO}_{2}$ particles.

Our previous research has shown the amounts of DPAA adsorbed by absorbent declined with increasing $\mathrm{pH}$ value or competing adsorbates (e.g. dissolved organic materials (DOM), phosphorus) (Wang et al., 2013). Thus, it can be inferred that increasing $\mathrm{pH}$ value and contents of DOM and phosphorus inhibited the absorption of DPAA by $\mathrm{TiO}_{2}$ particles. In addition, the ionic strength $(I)$ of soils can be calculated from the simple linear equation of ionic strength and electrical conductivity $(E C)$ (Fang et al., 2009): $I=0.0127 \times E C$. Thus, the higher EC indicates the higher ionic strength which can accelerate the agglomeration of $\mathrm{TiO}_{2}$ particles, reduce their surface active sites for DPAA adsorption, and then decreased the absorption of DPAA by $\mathrm{TiO}_{2}$ (von der Kammer et al., 2010). In summary, some selected soil properties (pH, EC or I, content of DOM and phosphorous) can affect the removal efficiency of DPAA by $\mathrm{TiO}_{2}$ PCO by controlling the adsorption of DPAA onto $\mathrm{TiO}_{2}$ particles.

\subsubsection{Effect of soil properties on generation of $\mathrm{OH} \bullet$ by $\mathrm{TiO}_{2}$-ESR evidences}

Here, the effects of soil properties on the generation of $\mathrm{OH} \bullet$ by $\mathrm{TiO}_{2}$ were also studied and the results show that these soil properties (listed above) can also influence the generation of $\mathrm{OH} \bullet$ by $\mathrm{TiO}_{2}$.

As shown in Fig. 3, Firstly, in acid (pH 3.0, Fig. 3f) or alkaline (pH 9.0, Fig. $3 g$ ) conditions the $\mathrm{OH} \bullet$ intensities in the soil clay (hematite) and $\mathrm{TiO}_{2}$ mixture were lower than those at $\mathrm{pH} 5.5$ (Fig. 3b). The $\mathrm{pH}$ values of the tested soils ranged from 4.5 to 6.8 and it could be inferred in this study soil $\mathrm{pH}$ could inhibit the generation efficiency of $\mathrm{OH} \bullet$ by $\mathrm{TiO}_{2}$ as it did on the adsorption of DPAA by $\mathrm{TiO}_{2}$. Furthermore, the $\mathrm{OH} \cdot$ intensity was amplified markedly by ionic strength $\left(\mathrm{SO}_{4}^{2-}\right)$ increasing (Fig. 3j-1). However, as mentioned above, the removal efficiency of DPAA by $\mathrm{TiO}_{2}$ in soil was inhibited by increasing ionic strength. This suggests that the removal efficiency of DPAA was affected more by the inhibition of ionic strength on the adsorption of DPAA by $\mathrm{TiO}_{2}$ than the promotion of ionic strength on $\mathrm{OH} \bullet$ generation. In addition, under the same total ionic strengths, $\mathrm{PO}_{4}^{3-}$ lowered the $\mathrm{OH} \bullet$ intensity slightly, but did not enhance the inhibition by increasing phosphate concentration (Fig. 3h, i). This also indicates the negative effect of $\mathrm{PO}_{4}^{3-}$ contents on the degradation efficiency of DPAA depended more on the competition of $\mathrm{PO}_{4}^{3-}$ with DPAA for adsorption sites on $\mathrm{TiO}_{2}$ particles than the effect of $\mathrm{PO}_{4}^{3-}$ on $\mathrm{OH} \bullet$ generation. Lastly, $\mathrm{DOM}$ was found to enhance the $\mathrm{OH} \bullet$ intensity at a lower concentration $\left(4 \mathrm{mg} \mathrm{L}^{-1}\right)$ (Fig. $3 \mathrm{~m}$ ) but inhibited the generation of $\mathrm{OH} \bullet$ gradually as its concentration increased (Fig. 3n, o). This result could be explained that DOM acted as both a photo-sensitizer of $\mathrm{TiO}_{2}$ at low concentration (Stylidi et al., 2004) and a scavenger of $\mathrm{OH} \bullet$ at high concentration. This suggests that DOM can suppress the removal of DPAA by $\mathrm{TiO}_{2}$ by prohibiting the adsorption of DPAA on $\mathrm{TiO}_{2}$ particles and the generation of $\mathrm{OH} \bullet$ by $\mathrm{TiO}_{2}$.

The effects of selected soil properties on the generation of $\mathrm{OH} \bullet$ by $\mathrm{TiO}_{2}$ could be attributed to the charge transferring from the excited $\mathrm{TiO}_{2}$ to soil clays, which was induced by the electrostatic interaction between the soli clays and $\mathrm{TiO}_{2}$ particles in various solutes (Zhou et al., 2012) (the mechanism was detailed in SI).

In conclusion, soil $\mathrm{pH}$, ionic strength (or electrical conductivity), and the contents of phosphorous and DOM can influence the removal efficiency of DPAA by affecting both the generation of $\mathrm{OH}$ by $\mathrm{TiO}_{2}$ and the adsorption of DPAA onto $\mathrm{TiO}_{2}$ particles, and the former may be less important than the latter in deciding the degradation efficiency of DPAA in soils by $\mathrm{TiO}_{2}$ PCO.

\section{Conclusions}

More than $90 \%$ of DPAA was degraded in $\mathrm{TiO}_{2}$ slurry under UV irradiation and arsenate was found to be the main end-product. Photodegradation experiments in soil showed this remediation method by $\mathrm{TiO}_{2}$ could also obtain satisfactory removal efficiency which was affected by both manipulating external factors and soil properties.
Soil:water ratio was found to have the largest impact on the degradation efficiency perhaps due to dilution of the soil slurry and enhancement of light penetration. Removal efficiency showed negative relationships with soil $\mathrm{pH}$, ionic strength, organic matter content, total phosphorus, all of which could affect the amounts of DPAA adsorbed onto $\mathrm{TiO}_{2}$ particles and the generation of $\mathrm{OH} \bullet$ by $\mathrm{TiO}_{2}$. The ecological toxicity and the recycling of the soil after photocatalytic treatment must be monitored in future studies. It is also worth being mentioned, soils amended with nanocrystalline $\mathrm{TiO}_{2}$ can be regarded as Technosols (Yao et al., 2009) with high surface areas, and could be used as adsorbents for heavy metal immobilization in contaminated fields or wastewater treatment. This hypothesis is worth of study for recycling these treated soils.

\section{Acknowledgment}

This work was supported by the National Natural Science Foundation of China (Nos. 41230858 and 41171248).

\section{Appendix A. Supplementary data}

Supplementary data to this article can be found online at http://dx. doi.org/10.1016/j.scitotenv.2015.09.023.

\section{References}

Bachman, J., Patterson, H.H., 1999. Photodecomposition of the carbamate pesticide carbofuran: kinetics and the influence of dissolved organic matter. Environ. Sci. Technol. 33, 874-881.

Balmer, M.E., Goss, K.U., Schwarzenbach, R.P., 2000. Photolytic transformation of organic pollutants on soil surfaces-an experimental approach. Environ. Sci. Technol. 34, 1240-1245.

Beltran, F.J., Garcia-Araya, J., Alvarez, P., Rivas, J., 1998. Aqueous degradation of atrazine and some of its main by-products with ozone hydrogen peroxide. J. Chem. Technol. Biotechnol. 71 (4), 345-355.

Chong, M.N., Jin, B., Chow, C.W.K., Saint, C., 2010. Recent developments in photocatalytic water treatment technology: a review. Water Res. 44, 2997-3027.

Dai, K., Peng, T.Y., Chen, H., Zhang, R.X., Zhangi, Y.X., 2008. Photocatalytic degradation and mineralization of commercial methamidophos in aqueous Titania suspension. Environ. Sci. Technol. 42, 1505-1510.

Daus, B., Hempel, M., Wennrich, R., Weiss, H., 2010. Concentrations and speciation of arsenic in groundwater polluted by warfare agents. Environ. Pollut. 158, 3439-3444.

Daus, B., Mattusch, J., Wennrich, R., Weiss, H., 2008. Analytical investigations of phenyl arsenicals in groundwater. Talanta 75, 376-379.

Davezza, M., Fabbri, D., Pramauro, E., Prevot, A.B., 2013. Photocatalytic degradation of chlorophenols in soil washing wastes containing Brij 35. Correlation between the degradation kinetics and the pollutants-micelle binding. Environ. Sci. Pollut. Res. 20, 3224-3231.

Fang, G.D., Gao, J., Dionysiou, D.D., Liu, C., Zhou, D.M., 2013. Activation of persulfate by Quinones: free radical reactions and implication for the degradation of PCBs. Environ. Sci. Technol. 47 (9), 4605-4611.

Fang, J., Shan, X.Q., Wen, B., Lin, J.M., Owens, G., 2009. Stability of titania nanoparticles in soil suspensions and transport in saturated homogeneous soil columns. Environ. Pollut. 157, 1101-1109.

Fujishima, A., Rao, T.N., Tryk, D.A., 2000. $\mathrm{TiO}_{2}$ photocatalysts and diamond electrodes. Electrochim. Acta 45, 4683-4690.

Gonder, Z.B., Kaya, Y., Vergili, I., Barlas, H., 2010. Optimization of filtration conditions for CIP wastewater treatment by nanofiltration process using Taguchi approach. Sep. Purif. Technol. 70, 265-273.

Guan, L., Hisatomi, S., Fujii, K., Nonaka, M., Harada, N., 2012a. Enhanced transformation of diphenylarsinic acid in soil under sulfate-reducing conditions. J. Hazard. Mater. 241, 355-362.

Guan, X.H., Du, J.S., Meng, X.G., Sun, Y.K., Sun, B., Hu, Q.H., 2012b. Application of titanium dioxide in arsenic removal from water: a review. J. Hazard. Mater. 215, 1-16.

Hanaoka, S., Nagasawa, E., Nomura, K., Yamazawa, M., Ishizaki, M., 2005. Determination of diphenylarsenic compounds related to abandoned chemical warfare agents in environmental samples. Appl. Organomet. Chem. 19, 265-275.

Hanaoka, S., Nomura, K., Wada, T., 2006. Determination of mustard and lewisite related compounds in abandoned chemical weapons (yellow shells) from sources in China and Japan. J. Chromatogr. A 1101, 268-277.

Harada, N., Takagi, K., Baba, K., Fujii, K., Iwasaki, A., 2010. Biodegradation of diphenylarsinic acid to arsenic acid by novel soil bacteria isolated from contaminated soil. Biodegradation 21, 491-499.

Hempel, M., Daus, B., Vogt, C., Weiss, H., 2009. Natural attenuation potential of phenylarsenicals in anoxic groundwaters. Environ. Sci. Technol. 43, 6989-6995.

Hong, C.S., Wang, Y.B., Bush, B., 1998. Kinetics and products of the $\mathrm{TiO}_{2}$ photocatalytic degradation of 2-chlorobiphenyl in water. Chemosphere 36, 1653-1667.

Huang, Q.D., Hong, C.S., 2000. $\mathrm{TiO}_{2}$ photocatalytic degradation of PCBs in soil-water systems containing fluoro surfactant. Chemosphere 41, 871-879. 
Ishii, K., Tamaoka, A., Otsuka, F., Iwasaki, N., Shin, K., Matsui, A., Endo, G., Kumagai, Y., Ishii, T., Shoji, S., Ogata, T., Ishizaki, M., Doi, M., Shimojo, N., 2004. Diphenylarsinic acid poisoning from chemical weapons in Kamisu, Japan. Ann. Neurol. 56, 741-745.

Ishizaki, M., Yanaoka, T., Nakamura, M., Hakuta, T., Ueno, S., Komura, M., Shibata, M. Kitamura, T., Honda, A., Doy, M., Ishii, K., Tamaoka, A., Shimojo, N., Ogata, T., Nagasawa, E., Hanaoka, S., 2005. Detection of bis(diphenylarsine)oxide, diphenylarsinic acid and phenylarsonic acid, compounds probably derived from chemical warfare agents, in drinking well water. J. Health Sci. 51, 130-137.

Jiang, W., Zhang, S., Shan, X., Feng, M., Zhu, Y., Maclaren, R., 2005. Adsorption of arsenate on soils. Part 1: Laboratory batch experiments using 16 Chinese soils with different physiochemical properties. Environ. Pollut. 138, 278-284.

Konstantinou, I.K., Albanis, T.A., 2004. $\mathrm{TiO}_{2}$-assisted photocatalytic degradation of azo dyes in aqueous solution: kinetic and mechanistic investigations-a review. Appl. Catal. B Environ. 49, 1-14.

Ma, L.Q., Komar, K.M., Tu, C., Zhang, W.H., Cai, Y., Kennelley, E.D., 2001. A fern that hyperaccumulates arsenic-a hardy, versatile, fast-growing plant helps to remove arsenic from contaminated soils. Nature 409, 579.

Maejima, Y., Murano, H., Iwafune, T., Arao, T., Baba, K., 2011. Adsorption and mobility of aromatic arsenicals in Japanese agricultural soils. Soil Sci. Plant Nutr. 57, 429-435.

Minero, C., Mariella, G., Maurino, V., Vione, D., Pelizzetti, E., 2000. Photocatalytic transformation of organic compounds in the presence of inorganic ions. 2. Competitive reactions of phenol and alcohols an a titanium dioxide-fluoride system. Langmuir 16 (23), 8964-8972.

Montgonery, D.C., 2001. Design and Analysis of Experiments. fifth ed. John Wiley, New York.

Nakamiya, K., Nakayama, T., Ito, H., Edmonds, J.S., Shibata, Y., Morita, M., 2007. Degradation of arylarsenic compounds by microorganisms. FEMS Microbiol. Lett. 274, 184-188.

Ng, A.M.C., Chan, C.M.N., Guo, M.Y., Leung, Y.H., Djurisic, A.B., Hu, X., Chan, W.K., Leung, F.C.C., Tong, S.Y., 2013. Antibacterial and photocatalytic activity of $\mathrm{TiO}_{2}$ and $\mathrm{ZnO}$ nanomaterials in phosphate buffer and saline solution. Appl. Microbiol. Biotechnol. 97, 5565-5573.

Qu, S., Kolodziej, E.P., Cwiertny, D.M., 2012. Phototransformation rates and mechanisms for synthetic hormone growth promoters used in animal agriculture. Environ. Sci. Technol. 46, 13202-13211.

Stylidi, M., Kondarides, D.I., Verykios, X.E., 2004. Visible light-induced photocatalytic degradation of Acid Orange 7 in aqueous $\mathrm{TiO}_{2}$ suspensions. Appl. Catal. B Environ. 47, 189-201.

Tu, A.T., 2011. Chemical weapons abandoned by the Imperial Japanese Army in Japan and China at the end of World War II. Toxin Rev. 30, 1-5.
Von der Kammer, F., Ottofuelling, S., Hofmann, T., 2010. Assessment of the physicochemical behavior of titanium dioxide nanoparticles in aquatic environments using multi-dimensional parameter testing. Environ. Pollut. 158, 3472-3481.

Wada, T., Nagasawa, E., Hanaoka, S., 2006. Simultaneous determination of degradation products related to chemical warfare agents by high-performance liquid chromatography/mass spectrometry. Appl. Organomet. Chem. 20, 573-579.

Wang, A.A., Li, S.X., Teng, Y., Liu, W.X., Wu, L.H., Zhang, H.B., Huang, Y.J., Luo, Y.M., Christie, P., 2013. Adsorption and desorption characteristics of diphenylarsenicals in two contrasting soils. J. Environ. Sci. 25, 1172-1179.

Wang, A.A., Teng, Y., Luo, Y.M., 2014. Study on the photo-catalytical degradation of diphenylarsinic acid by $\mathrm{TiO}_{2}$ (P25). Environ. Sci. 35, 3800-3806 (In Chinese).

Williams, P.N., Villada, A., Deacon, C., Raab, A., Figuerola, J., Green, A.J., Feldmann, J., Meharg, A.A., 2007. Greatly enhanced arsenic shoot assimilation in rice leads to elevated grain levels compared to wheat and barley. Environ. Sci. Technol. 41 (19), 6854-6859.

Wu, C., Ye, Z.H., Shu, W.S., Zhu, Y.G., Wong, M.H., 2011. Arsenic accumulation and speciation in rice are affected by root aeration and variation of genotypes. J. Exp. Bot. 62 (8), 2889-2898

Xu, T., Kamat, P.V., Joshi, S., Mebel, A.M., Cai, Y., O'Shea, K.E., 2007a. Hydroxyl radical mediated degradation of phenylarsonic acid. J. Phys. Chem. A 111, 7819-7824.

Xu, T., Cai, Y., O'Shea, K.E., 2007b. Adsorption and photocatalyzed oxidation of methylated arsenic species in $\mathrm{TiO}_{2}$ suspensions. Environ. Sci. Technol. 41, 5471-5477.

Xu, Z.H., Jing, C.Y., Li, F.S., Meng, X.G., 2008. Mechanisms of photocatalytical degradation of monomethylarsonic and dimethylarsinic acids using nanocrystalline titanium dioxide. Environ. Sci. Technol. 42, 2349-2354.

Yang, K., Lin, D.H., Xing, B.S., 2009. Interactions of humic acid with nanosized inorganic oxides. Langmuir 25, 3571-3576.

Yao, F.X., Macias, F., Virgel, S., Blanco, F., Jiang, X., Arbestain, M.C., 2009. Chemical changes in heavy metals in the leachates from Technosols. Chemosphere 77, 29-35.

Zhang, L.H., Li, P.J., Gong, Z.Q., Li, X.M., 2008. Photocatalytic degradation of polycyclic aromatic hydrocarbons on soil surfaces using $\mathrm{TiO}_{2}$ under UV light. J. Hazard. Mater. 158, 478-484.

Zheng, S., Cai, Y., O'Shea, K.E., 2010. TiO2 photocatalytic degradation of phenylarsonic acid. J. Photochem. Photobiol., A 210, 61-68.

Zhou, D.X., Abdel-Fattah, A.I., Keller, A.A., 2012. Clay particles destabilize engineered nanoparticles in aqueous environments. Environ. Sci. Technol. 46, 7520-7526.

Zhu, X.D., Wang, Y.J., Sun, R.J., Zhou, D.M., 2013. Photocatalytic degradation of tetracycline in aqueous solution by nanosized $\mathrm{TiO}_{2}$. Chemosphere 92, 925-932. 